UNIVERSIDADE DE BRASÍLIA

CENTRO DE EXCELÊNCIA EM TURISMO

CURSO DE GESTÃO E MARKETING EM TURISMO

\title{
O CINE BRASÍLIA COMO PATRIMÔNIO CULTURAL DA CIDADE
}

\author{
Aluna: Francisca Vilany Kehrle \\ Orientador: Msc José Luiz Niederauer Pantoja
}

Monografia apresentada ao Centro de Excelência em Turismo da UnB, como requisito parcial para obtenção do certificado de especialista em Turismo 
UNIVERSIDADE DE BRASÍLIA

CENTRO DE EXCELÊNCIA EM TURISMO

CURSO DE GESTÃO E MARKETING EM TURISMO

O CINE BRASÍLIA COMO PATRIMÔNIO CULTURAL DA CIDADE 


\section{SUMÁRIO}

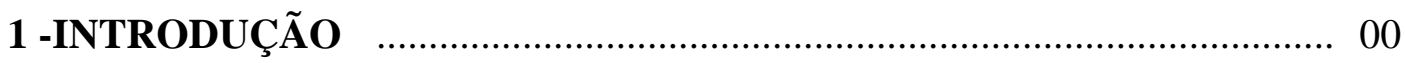

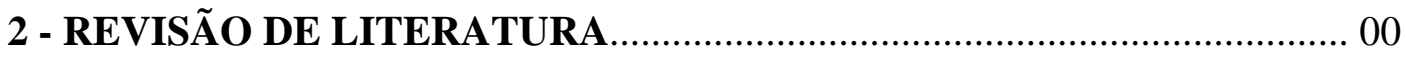

2.1 - Conceito de Turismo............................................................................ 00

2.2 - O que significa Patrimônio Histórico.................................................... 00

2.3 - A política de Patrimônio no Brasil........................................................... 00

2.4 - O Instituto do Patrimônio Histórico e Artístico Nacional (IPHAN).. 00

2.4.1-Origem.......................................................................................

2.5 - Conceito de Patrimônio Cultural pela Unesco...................................... 00

2.6 - Bens brasileiros que integram a Lista do Patrimônio Histórico

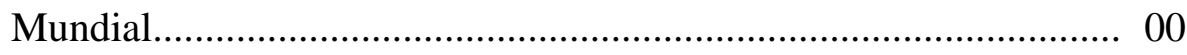

2.7 - Brasília como Patrimônio Cultural da Humanidade ........................... 00

2.8 -O Cine Brasília.......................................................................... 00

2.9 - Festival de Brasília do Cinema Brasileiro............................................ 00

2.10 - A Escola vai ao Cinema.................................................................... 00

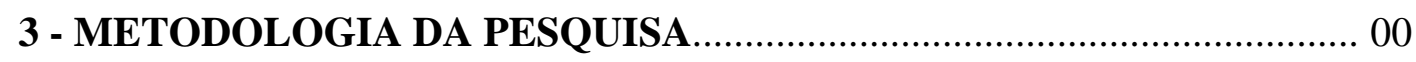

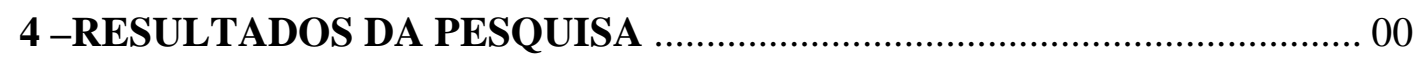

4.1.Observações sobre a programação......................................................... 00

4.2 -Observações sobre os valores agregados ao serviço................................00

4.3 - Observações sobre as condições físicas e materiais do cinema.......... 00

4.3.1- Área externa do Cinema................................................................00

4.3.2-Área interna do Cinema..................................................................

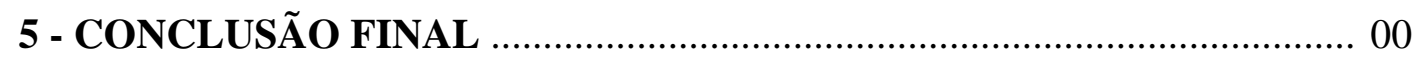

5.1 - O Cinema como patrimônio histórico ……………………………..... 00 
5.2- O Cinema e sua programação

00

5.3- A importância da conservação do Cinema e os serviços agregados .. 00

6 - REFERÊNCIAS BIBLIOGRÁFICAS

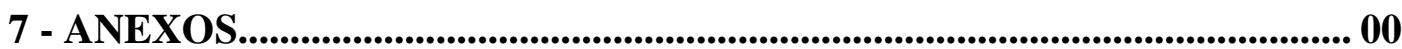

7.1 - O Cinema que faz história $\quad$.................................................... 00

7.2- O cine que é a cara do Festival .................................................... 00

7.3- A reforma

7.4- Cinzas do Cine Brasília........................................................................ 00

7.5 -Maquiagem nova para o Cine Brasília................................................00

7.6- Cine Brasília inaugura fase democrática............................................... 00

7.7- A missão de repensar o Cine Brasília...................................................00

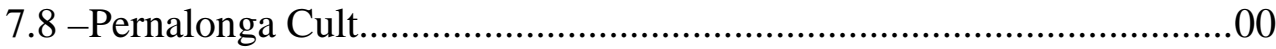

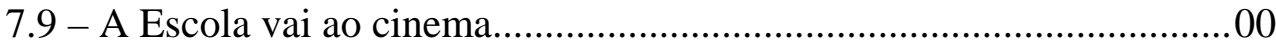




\section{1-INTRODUÇÃO}

A finalidade desta pesquisa é relatar a história do Cine Brasília, um dos espaços culturais e de lazer mais importantes na vida dos primeiros habitantes do Distrito Federal. Deseja-se enfatizar a importância deste espaço cultural como patrimônio histórico e como lugar de memória dos pioneiros da Capital, defendendo a necessidade de preservá-lo e revitalizá-lo, ressaltando pontos positivos e negativos da sua gestão, por meio de observações a respeito de suas instalações físicas e materiais, da condução de sua programação e na utilização dos valores que o estabelecimento agrega.

Os dados da pesquisa começaram a ser tabulados em 2001, mas foram transformados em informações que nortearam o presente trabalho, em 2003. No primeiro capítulo, se buscará definir na pesquisa, um conceito de turismo, o que significa patrimônio histórico e cultural e sua relação com o turismo, serão feitos comentários sobre a política de patrimônio no Brasil, de Brasília como Patrimônio Cultural da Humanidade, e será resgatada a história do Cine Brasília e do Festival de Brasília do Cinema Brasileiro, que acontece no local anualmente. No segundo capítulo, são indicados os métodos que foram utilizados para desenvolver a pesquisa. Os resultados alcançados são apresentados no terceiro capítulo, e o quarto capítulo é dedicado às sugestões como parte da conclusão final. 


\section{2 - REVISÃO DE LITERATURA}

\section{1-Conceito de Turismo}

Segundo definição da Organização Mundial do Turismo (OMT), a atividade do Turismo significa o deslocamento de pessoas de seu domicílio cotidiano, por no mínimo 24 horas, com a finalidade de retorno, e quem faz turismo é chamado de turista. Os turistas viajam por muitas razões: trabalho, descanso, curiosidade, saúde, divertimento, aventura, para adquirir conhecimento etc.

O hábito de viajar é antigo, mas o turismo só começou a se organizar em meados do século XIX, e se transformou em uma atividade de massa muito significativa em termos econômicos na década de 1950, após a Segunda Guerra Mundial.

O primeiro a transformar as viagens em negócio gerador de lucros foi o inglês Thomas Cook que, em 1841, organizou a primeira excursão de Lucester a Loughborough, no Reino Unido, dando início ao turismo moderno.

O turismo nasceu com o capitalismo, no século 19, e acompanhou o seu desenvolvimento. Várias conseqüências da segunda fase capitalista ajudaram a fortalecer essa atividade, no século passado. Entre as principais, podemos citar a construção de motores a vapor para equipar navios, de locomotivas, ferrovias, estações ferroviárias e portos.

A evolução nos meios de transportes ajudou a reduzir distâncias e a superar fronteiras. Os novos recursos de engenharia e arquitetura que revolucionaram a construção civil, também colaboraram para a expansão da atividade turística. Torres de observação (a Torre Eiffel de Paris, por exemplo), e edifícios para os mais variados usos começaram a surgir com base em estruturas de ferro (TRIGO, 1993, p. 15,16). 
Aos poucos, os meios de transportes ficaram mais rápidos, seguros e confortáveis. Mais tarde, a evolução do transporte aéreo ganhou destaque contribuindo para uma acelerada modernização do setor, por meio de uma maior rapidez e diminuição de custos. Esses recursos levaram uma parcela da população do planeta a ter acesso fácil a locais e maravilhas espalhados pelos vários continentes.

Atualmente o fenômeno turístico é analisado dentro do contexto que envolve a cultura, as artes e o lazer, pois a valorização que o turismo sofreu ao longo dos últimos anos o transformou em um processo social abrangente, que envolve novas formações econômicas que, com o auxílio de novas tecnologias, produziram novos estilos de vida no mundo todo.

Ainda, segundo a Organização Mundial do Turismo (OMT), o turismo cultural seria caracterizado pela procura por estudos, cultura, artes cênicas, festivais, monumentos históricos ou arqueológicos, manifestações folclóricas ou peregrinações. Essa definição, para alguns autores, é tão ampla que ocasiona, paradoxalmente, o estreitamento da visão de turismo cultural, quando, no momento, o reconhecimento da diversidade torna-se um paradigma e pode-se dizer que, assim como não há um turista genérico, não há um turismo cultural genérico (cf. Norris Nicholson 1997, pp. 118-120, em Margarita Barretto, pp. 20).

O autor quer dizer que o turismo cultural é tão amplo, que existem apelos para que seja realizada uma subdivisão dos conceitos turismo cultural, turismo de arte e turismo histórico, que, muitas vezes, são usados como sinônimos. Os turistas também têm sido estudados pela sociologia e enquadrados em tipologias (BARRETTO, 2000, p. 20).

Decorrido meio século da expansão em grande escala da atividade turística em todas as partes do mundo, ganham força, em vários países, em especial nos meios universitários e científicos, os questionamentos a respeito das conseqüências que o fenômeno tem para o meio ambiente natural e cultural. 
Os impactos do turismo na natureza e nas populações receptoras e seus efeitos sobre os bens culturais, tais como o patrimônio histórico, são algumas das questões importantes. 


\section{2 - O que significa Patrimônio Histórico}

A origem etimológica de "patrimônio" vem do latim patrimoniu, encontrando-se associado à idéia de herança paterna, bens de família e riqueza (HOLANDA, 1977, p. 355).

A noção de patrimônio, relacionada pelos antigos romanos à herança familiar, privada, assumiu, a partir do Renascimento, uma conotação de coisa pública em razão da valorização da cultura material da Antiguidade.

A função do poder público de proteger o patrimônio foi sistematizada na França, logo após a Revolução Francesa. A idéia de o governo zelar pelo conjunto de bens que compõem a herança social considerou a materialidade dos objetos, seu poder de testemunhar o passado, de fornecer informações sobre ele e de atrair a atenção.

O patrimônio pode ser classificado por duas grandes divisões: natureza e cultura. Patrimônio natural são as riquezas que estão no subsolo, tanto as florestas quanto às jazidas. Quanto ao patrimônio cultural, esse conceito vem sendo ampliado à medida que se revisa o conceito de cultura (BARRETTO, 2000, p. 9).

De acordo com BARRETTO (2000, p. 9)até a primeira metade do século XX, patrimônio cultural foi sinônimo de obras monumentais, obras de arte consagradas, propriedades de grande luxo, associadas às classes dominantes, pertencentes à sociedade política, ou civil.

Atualmente a noção de patrimônio cultural tornou-se muito mais ampla, incluindo não só os bens tangíveis como também os intangíveis, as manifestações artísticas e todo o fazer humano, além da cultura de classes menos favorecidas, e não apenas a daquela que representa as elites. Por isso, segundo alguns autores, o conceito "legado cultural” parece mais adequado do que o de "patrimônio". 
Em 1972, durante a convenção do Patrimônio Mundial da Organização das Nações Unidas para a Educação, Ciência e Cultura (Unesco), foram feitas algumas advertências sobre a verdadeira situação do patrimônio cultural, que cada vez mais, encontrava-se ameaçado de destruição. Tais ameaças só poderiam ser banidas, caso fossem adotadas políticas de preservação eficazes.

Preservar significa "proteger, resguardar, evitar que alguma coisa seja atingida por alguma outra que lhe possa ocasionar dano”. A medida legal mais concreta para proteger o patrimônio é o tombamento que consiste num registro do bem num "livro de tombo", em cujas páginas ficam registrados os bens considerados valiosos e sujeitos às leis de preservação do patrimônio, isso implica que não podem ser demolidos nem modificadas em seu aspecto externo ou em suas características essenciais, implicando também que, num raio de 300 metros, nada pode ser modificado (BARRETTO, 2000, p. 14).

Para que um determinado bem cultural possa ser considerado por alguém como possuidor de um certo valor, ele deve ser avaliado por especialistas. No caso do Brasil, essa avaliação será feita por especialistas do Instituto do Patrimônio Histórico e Artístico Nacional (Iphan), que preparam um relatório técnico, com os resultados da avaliação do bem em questão, e recomendam ou não o tombamento. O “tombamento" de um bem cultural e sua inclusão em um dos livros do Tombo é um estágio final de um longo processo (BARBOSA, 2001, p. 80).

O tombamento consiste num registro do bem num "livro de tombo", em cujas páginas ficam registrados os bens considerados valiosos e sujeitos às leis de preservação do patrimônio, o que implica não poderem ser demolidos nem modificados em seu aspecto externo ou em suas características essenciais, implicando também que, num raio de 300 metros, nada pode ser modificado (BARRETTO, 2000, p.14). 


\section{3 - A política de Patrimônio no Brasil}

Segundo BARBOSA (2001, p. 77), a primeira notícia que se tem de iniciativa visando à proteção de monumentos históricos, no Brasil, data de meados do século XVIII. Dom André de Melo, Conde das Galveias, Vice-Rei do Estado do Brasil, de 1735 a 1749, ao tomar conhecimento das intenções do governo de Pernambuco a respeito de construções deixadas pelos holandeses, escreveu-lhe uma carta na qual demonstra sua preocupação com a proteção dos monumentos históricos.

Embora tivesse como um de seus interesses os estudos históricos, durante seu reinado, o imperador Dom Pedro II não tomou nenhuma providência para organizar efetivamente a proteção aos monumentos nacionais. (BARBOSA, 2001, p. 77, 78)

O primeiro projeto visando organizar a defesa dos monumentos históricos e artísticos do país, foi apresentado na Câmara dos Deputados, em 1923, e surtiu pouco efeito. Em 1924, houve o deslocamento para a esfera estadual, quando foi apresentado projeto de proteção em Minas Gerais.

A prática de preservação do patrimônio se estabeleceu no Brasil na década de 1930. Em 1934, o Governo iniciou a organização de um serviço de proteção do patrimônio e das obras de arte.

Até a década de 1980, os “objetos” dignos de proteção estavam relacionados aos colonizadores e as classes privilegiadas. Até então, o que era produzido por pobres e negros não era reconhecido como representação de história e cultura nacionais.

Em 1980, quando os movimentos sociais lutavam pela democratização do País e o efetivo exercício dos direitos de cidadania, segmentos sociais e étnicos começaram a ter reconhecidos seus papéis de construtores da sociedade, da história e da cultura brasileira (RODRIGUES, 2001, p. 17). 
A partir de então, em especial na década de 1980, o número de leis voltadas para preservação do patrimônio cresceu, demonstrando, assim, a preocupação da sociedade brasileira para com o assunto. Contudo, as formas legais de proteção adotadas não foram ampliadas e o tombamento continuou a ser a forma predominante.

Hoje, além do objetivo de representar o passado histórico e cultural de uma sociedade, o patrimônio é valorizado pelo poder público como um bem cultural e parte da sociedade o vê como um fator de qualidade de vida. Essa visão é fruto de uma nova conjuntura internacional de mudanças culturais, sociais, de mentalidade, e do crescimento econômico.

A partir de então, em especial na década de 1980, o número de leis voltadas para preservação do patrimônio cresceu, demonstrando, assim, a preocupação da sociedade brasileira para com o assunto. Contudo, as formas legais de proteção adotadas não foram ampliadas e o tombamento continua a ser a forma predominante. 


\section{4 - O Instituto do Patrimônio Histórico e Artístico Nacional (IPHAN)}

\subsection{1- Origem}

O primeiro órgão federal criado para cuidar da preservação do patrimônio foi o Serviço de Patrimônio Histórico e Artístico Nacional (Sphan), a mais antiga entidade oficial de preservação dos bens culturais na América Latina. Criado em 13 de janeiro de 1937, pela Lei n ${ }^{\circ}$ 378, no Governo de Getúlio Vargas, em 1946, por meio do DecretoLei $\mathrm{n}^{\circ}$ 8.534, de 21 de janeiro, o Sphan passou a se chamar Dphan, e, por meio do Decreto $n^{\circ}$ 66.967, de 27/06/1970 se transforma em Instituto do Patrimônio Histórico e Artístico Nacional (IPHAN), hoje vinculado ao Ministério da Cultura.

A criação do Sphan representou o primeiro passo de uma política centrada no tombamento e na preservação do que se julgava na época, como patrimônio histórico. De acordo com a lei, para serem considerados patrimônio os bens devem ser inscritos em um dos quatro "Livros do Tombo", conforme previsto no artigo 4 do decreto-lei $\mathrm{n}^{\circ}$ 25, de 30 de novembro de 1937.

O órgão teve como base um anteprojeto de autoria do escritor Mário de Andrade. O decreto-lei de 1937 teve como base a legislação francesa, na medida em que focaliza o monumento ou o edifício excepcional - por qualidades artísticas ou por qualidades históricas.

O anteprojeto elaborado por Mário de Andrade foi solicitado pelo ministro da Educação e Saúde de Vargas, Gustavo Capanema. A tarefa de implantação do órgão ficou a cargo do intelectual Rodrigo Melo Franco de Andrade que, para realizar a tarefa contou com a ajuda do próprio Mário de Andrade, Manuel Bandeira, Afonso Arinos, Carlos Drummond de Andrade e Lúcio Costa.

Rodrigo Mello Franco tornou-se diretor do Sphan, em 1936, permanecendo no órgão até sua morte, em 1969. Dirigiu a Revista Anual do Patrimônio Histórico e foi responsável por monografias publicadas pelo Sphan. 
A solicitação de Capanema a Mário de Andrade foi feita em 1936 e, em 30 de novembro de 1937, foi promulgado o decreto $\mathrm{n}^{\circ} 25$, que organiza a "proteção do patrimônio histórico e artístico nacional”.

O decreto $\mathrm{n}^{\circ} 25$ considera Patrimônio Cultural o “conjunto de bens móveis ou imóveis existentes no País e cuja conservação seja de interesse público, quer por sua vinculação a fatos memoráveis da História do Brasil, quer por seu excepcional valor arqueológico ou etnográfico, bibliográfico ou artístico”.

Há mais de 60 anos, o IPHAN vem realizando um trabalho de fiscalização, proteção, identificação, restauração, preservação e revitalização dos monumentos, sítios, e bens móveis do País.

O IPHAN, atualmente, desenvolve sua ação junto à sociedade por meio de 29 unidades com autonomia orçamentária-financeira. A Administração Central do IPHAN funciona em Brasília (DF), e o órgão engloba, ainda,.o Palácio Gustavo Capanema, no Rio de Janeiro; 15 Superintendências Regionais e 19 Sub-Regionais; 10 museus: Nacional de Belas Artes, Histórico Nacional, Imperial, da República, da Inconfidência, Lasar Segall, Villa-Lobos, Raymundo Ottoni de Castro Maya, de Biologia Professor Mello Leitão; 18 Museus Regionais; 9 Casas Históricas e 7 Escritórios Técnicos; 3 Unidades Especiais: Paço Imperial, Sítio Roberto Burle Marx, Cinemateca Brasileira.

O trabalho do IPHAN pode ser reconhecido nos mais de 16 mil edifícios tombados, 50 centros e conjuntos urbanos, 5 mil sítios arqueológicos cadastrados, mais de um milhão de objetos, incluindo acervo museológico, cerca de 250 mil volumes bibliográficos, documentação arquivística e registros fotográficos, cinematográficos e videográficos (Site: www.iphan.gov.br: 13.01.2004) 


\section{5 - Conceito de Patrimônio Cultural pela Unesco}

Em 1972, a “Convenção Concernente à Proteção do Patrimônio Mundial, Cultural e Natural”, adotada pela Conferência Geral da Organização das Nações Unidas para a Educação, a Ciência e a Cultura (Unesco) discutiu e consagrou um conceito mais amplo de patrimônio. A Convenção adotou critérios e mecanismos que protegem e preservam, para as gerações futuras, cidades, monumentos, sítios naturais considerados de valor excepcional para toda a humanidade.

A Convenção estabeleceu que a natureza e a cultura são interdependentes e complementares, pois parte significativa da beleza das cidades, dos monumentos e dos conjuntos construídos pelo homem vem do ambiente e de paisagem em que eles se situam. Mesmo os sítios naturais mais selvagens e inóspitos são marcados pela atividade humana ao longo dos séculos (Boletim Informativo do IPHAN: Nov/Dez de 1992).

Em 1977, o Brasil assinou a Convenção do Patrimônio Mundial, Cultural e Natural instituída pela Unesco. Antes de ser acolhido como Patrimônio Mundial, o bem cultural ou natural, deve ser consagrado em seu próprio país como Patrimônio Nacional.

Por tratar-se de uma organização diplomática, a Unesco não possui mecanismos de intervenção direta sobre os bens que constituem a Lista do Patrimônio Mundial. Para fiscalizar e conservar os bens, a Organização atua por meio do órgão responsável, em cada país que detém o patrimônio, por sua preservação.

No caso do Brasil, de dois em dois anos a Unesco solicita do IPHAN relatório detalhado sobre o estado de conservação de cada um dos bens brasileiros que integram a Lista de Patrimônio Mundial.

Anualmente, o Comitê do Patrimônio Mundial se reúne e analisa novas proposições dos países signatários, acolhendo novos bens. 


\section{6 - Bens brasileiros que integram a Lista do Patrimônio Histórico Mundial}

- .Arquipélago Fernando de Noronha (PE);

- Atol das Rocas (RN);

- .Centro Histórico de Diamantina (MG);

- $\quad$.Centro Histórico de Goiás (GO);

- .Centro Histórico de Olinda (PE);

- .Centro Histórico de Salvador (BA);

- .Centro Histórico de São Luís (MA);

- .Cidade de Goiás (GO);

- . Conjunto Arquitetônico e Urbanístico de Ouro Preto

- (MG);

- .Conjunto Urbanístico, Arquitetônico e Paisagístico de

- Brasília (DF);

- .Complexo de Áreas Protegidas do Pantanal

- $\quad$ Matogrossense (MT/MS);

- .Conjunto de 25 Áreas de Mata Atlântica na divisa

- de São Paulo com o Paraná;

- Costa do Descobrimento no sul da Bahia e norte do Espírito Santo, com mais de 15.700 edificações a serem protegidas;

- .Parques Nacionais da Chapada dos Veadeiros e das Emas (GO);

- .Parque Nacional do Iguaçu (PR);

- .Parque Nacional do Jaú (AM);

- .Remanescentes da Igreja de São Miguel das Missões Jesuíticas dos Guaranis (RS);

- .Santuário do Bom Jesus de Matosinhos (MG);

- .Sítios Arqueológicos de São Raimundo Nonato, no

- $\quad$ Parque Nacional Serra da Capivara (PI). 


\section{7 - Brasília como Patrimônio Cultural da Humanidade}

Segundo o IPHAN, devido a algumas razões, Brasília é um objeto de preservação de maior complexidade. O Plano Piloto está legalmente protegido em três instâncias:

1) pelo governo do Distrito Federal, por meio do decreto $\mathrm{n}^{0} 10.829$, de 14 de outubro de 1987, que regulamenta o artigo 38 da Lei no 3.751, de 13 de abril de 1960 - primeira Lei Orgânica do DF;

2) pela resolução da Unesco, que determinou sua inscrição na Lista do Patrimônio Mundial, em 7 de dezembro de 1987;

3) pelo tombamento federal, em 14 de março de 1990 - inscrição no Livro do Tombo Histórico, $\mathrm{n}^{0}$ 532, regulado pelo decreto-lei $\mathrm{n}^{0}$ 25, de 30 de novembro de 1937, e regulamentado pela Portaria Sphan ${ }^{\circ}$ 004, de 13 de março de 1990, modificada pela Portaria IPHAN nº 314, de 8 de outubro de 1992.

Essa legislação determina a preservação da concepção urbanística de Brasília, de acordo com o projeto do Plano Piloto de Lúcio Costa. A área de proteção é muito extensa - a maior do mundo, enquanto sítio urbano tombado.

As características essenciais do Conjunto Urbanístico, Arquitetônico e Paisagístico de Brasília estão presentes nas quatro escalas, que estabelecem os elementos determinantes de um padrão de qualidade de vida: monumental, residencial, gregária e bucólica.

.Monumental - compreende todo o conjunto de edifícios, praças, gramados, bosques e avenidas que vai do Palácio da Alvorada, passando pela Praça dos Três

Poderes, Esplanada dos Ministérios, Estação Rodoviária, Torre de TV e Praça do Buriti até o fim do Eixo Monumental, em frente à Estação Rodoferroviária; 
.Residencial - é formada pelas chamadas Superquadras, incluindo o comércio local, igrejas, escolas, cinemas e serviços, bem como pelos conjuntos de casas na W3 Sul;

.Gregária - compreende os setores de serviços e de convivência coletiva: Comercial, Bancário, de Autarquias, Hoteleiro e de Diversões;

.Bucólica - se consubstancia nos gramados, passeios, bosques e jardins que permeiam e envolvem as Superquadras, as Entrequadras e conjuntos de casas e comércios locais, bem como nos parques, nos clubes, no Lago Paranoá e em sua orla. 


\section{8 -O Cine Brasília}

O Plano Piloto de Brasília, considerado Patrimônio Mundial da Humanidade desde 1987, além de um traçado urbanístico moderno, possui muitos edifícios e palácios famosos e representativos.

O Cine Brasília é uma das inúmeras construções da fase inicial de Brasília. Inaugurado dentro da programação comemorativa da transferência da capital brasileira para o Planalto Central, em 22 de abril de 1960, o cinema foi inaugurado junto com a Capital e é um marco importante na vida dos primeiros habitantes da cidade, incorporando-se, de imediato, ao seu lazer.

Projetado pelo arquiteto Oscar Niemeyer, o cinema foi construído dentro de 30 dias pela Construtora Pederneiras S/A, passando a pertencer à Companhia de Urbanização da Nova Capital (NOVACAP).

Construído com os melhores requintes de engenharia, conforto e projeto arquitetônico ousado, o cinema passou a ser freqüentado por toda população da cidade: senadores, deputados, ministros, embaixadores, intelectuais, motoristas, funcionários públicos, operários, entre outros.

Segundo matéria publicada no jornal (ver Anexo $n^{\circ} 1$ ), os filmes Anáguas a Bordo, com Gary Grant; A Canoa Furou, com Jerry Lewis e o Discípulo do Diabo, com Kirk Douglas, foram alguns dos grandes sucessos de bilheteria dentro do programa inaugural do Cinema

De 15 a 22 de novembro de 1965, teve início, no Cine Brasília, a $1^{a}$ Semana do Cinema Brasileiro, que, mais tarde, passou a se chamar Festival de Brasília do Cinema Brasileiro, que acontece anualmente. 
Em 1971, devido à má conservação pela Companhia Cinematográfica Luiz Severiano Ribeiro, o Cinema foi fechado, temporariamente. Durante um período de dois anos, o local ficou completamente abandonado. Segundo matérias de jornais da época (ver Anexo $\mathrm{n}^{\circ} 1$ ), o espaço foi transformado em depósito de lixo e abrigo de mendigos e de pessoas que viviam pelas ruas.

Os jornais informam que as paredes careciam de novo revestimento, os projetores estavam quebrados, as instalações elétricas e sanitárias danificadas, o sistema de som e o ar-condicionado encontravam-se em estado de degradação, e o edifício enfrentou até princípio de incêndio (Anexo 4).

No final de 1972, a NOVACAP retomou em juízo o cinema doando-o, em seguida, à Fundação Cultural do Distrito Federal (FCDF), que o recebeu totalmente danificado.

Para se converter em um verdadeiro "cinema de arte”, o Cine Brasília teve que passar por uma intensa reforma. O arquiteto Milton Ramos, autor do projeto inicial do cinema e membro da equipe de Oscar Niemeyer, foi o responsável pelo projeto de recuperação, que teve início na gestão do embaixador Wladimir Murtinho, na Fundação Cultural do Distrito Federal. Segundo informações veiculadas pela imprensa (Anexo 3), quase tudo precisava de reparos.

No dia 2 de julho de 1973, teve início a reforma. O piso, composto por uma rampa, foi substituído por degraus atapetados. As paredes foram revestidas, e uma delas foi decorada por um painel de Athos Bulcão - também responsável pela decoração inicial. A sala de espera foi totalmente mobiliada; jardins foram criados; o estacionamento ampliado e todos os equipamentos substituídos: projetores, arcondicionado, sistema de som, instalações elétricas e sanitárias etc.

De acordo com o coordenador de cinema da Secretaria de Cultura do Distrito Federal, Fernando Adolfo, houve diminuição no número de poltronas - de 1.250 passou para 607. Ele enfatizou que a medida visava dar mais conforto aos freqüentadores. 
Em 7 de julho de 1976, o Cine Brasília foi reinaugurado com a exibição dos filmes Pedra da Riqueza, de Vladimir Carvalho, e Lição de Amor, de Eduardo Escorel.

Um dos grandes responsáveis por transformar o Cine Brasília em referência para os cinéfilos cult brasilienses foi o baiano José Damata. Grande conhecedor da programação exibida em cine-clubes, Damata foi, durante muitos anos, programador de cinema da Fundação Cultural do Distrito Federal, a quem pertence o Cinema.

Em sua gestão, o público brasiliense chegou a lotar o cinema inúmeras vezes fato que ocorre, normalmente, durante o Festival de Brasília do Cinema Brasileiro. Filmes como A Flauta Mágica, de Ingmar Bergman, Estamos Todos Bem, de Giuseppe Tornatore, e Asas do Desejo, de Wim Wenders, levaram o público a formar longas filas para assistir às sessões.

Além da programação diária, com os filmes sendo exibidos, normalmente, em três sessões: às 17h, 19h e 21h, o Cinema mantém o projeto A Escola Vai ao Cinema que, de forma educativa, oferece duas sessões de filmes - às $10 \mathrm{~h}$ e às 15 , aos alunos do Ensino Fundamental das redes pública e privada de ensino do Distrito Federal.

O cinema possui equipamentos de última geração e tem acústica privilegiada som Dolby stereo digital. Em termos de acústica é considerado por muitos, “o melhor cinema do Brasil”. Dispõe de projetores modernos, de procedência italiana, e tela com dimensão de 14.00 x 6.30 metros. Muitos também consideram o cinema um dos melhores do País, em termos de espaço.

Lançamento de filmes nacionais e mostras de filmes estrangeiros, realizadas em parceria com entidades internacionais, como as Embaixadas dos países sediadas na Capital Federal, são outras grandes funções do Cine Brasília.

Há sete anos, o Cinema abriga o Café La Película, duas prateleiras e um balcão com exposição de livros, cartões, camisetas e outros objetos de valor artístico e literário. 
O valor do ingresso, atualmente, custa $\mathrm{R} \$ 6,00$ (seis reais), durante todos os dias da semana e nos feriados, preço bastante atraente para quem deseja assistir a um bom filme e ter alguns momentos de lazer.

Existem cerca de 17 funcionários trabalhando no Cinema. O serviço de limpeza, que é feito diariamente, é executado por empregados de empresa terceirizada e o café foi arrendado por meio de licitação. 


\section{9 - Festival de Brasília do Cinema Brasileiro}

Em 1965, aconteceu em Brasília a $1^{a}$ Semana do Cinema Brasileiro. O evento foi criado por uma comissão instituída pelo professor Cleantho Rodrigues Siqueira, presidente da Fundação Cultural do DF, e dirigida pelo intelectual e professor da Universidade de Brasília, Paulo Emílio Salles Gomes.

O filme A Hora e a Vez de Augusto Matraga, dirigido por Roberto Santos, baseado em conto de Guimarães Rosa, recebeu os prêmios de melhor filme, melhor diretor, melhor argumento, melhor diálogo e melhor ator da $1^{a}$ Semana de Cinema Brasileiro, que foi realizada no Cine Brasília.

Em 1967, a Semana passou a se chamar Festival de Brasília do Cinema Brasileiro. O crítico de cinema e escritor Paulo Emílio Salles Gomes, o cineasta Nélson Pereira dos Santos e o ensaísta-escritor de cinema belga de nacionalidade francesa JeanClaude Bernardet foram alguns dos intelectuais que tiveram papel fundamental na origem do festival brasiliense.

Quando nasceu a $1^{a}$ Semana de Cinema Brasileiro, que originou o Festival de Brasília do Cinema Brasileiro, estava no auge, no Brasil, o Cinema Novo, que tinha como lema “ Uma câmara na mão e uma idéia na cabeça”. Os cineastas Gláuber Rocha, Nélson Pereira dos Santos e Joaquim Pedro de Andrade são alguns nomes consagrados do movimento. Os filmes Deus e o Diabo na Terra do Sol (1964), de Gláuber Rocha, e Vidas Secas (1963), de Nélson Pereira dos Santos, inspirado no romance homônimo de Graciliano Ramos, foram alguns dos grandes filmes produzidos à época.

De 1969 a 1971, o Festival ocorreu no Cine Atlântida. De 1972 a 1974, durante o regime militar, o Festival não foi realizado. Em 1975, teve como sede o Cine Karim. Em 1976, o Festival volta ao Cine Brasília. Em 1987, retorna ao Karim. Em 1988, acontece no Parkshopping, e, a partir de 1989, volta ao Cine Brasília, onde se mantém até hoje. 
Para a pesquisadora Berê Bahia, coordenadora do livro 30 Anos de Cinema e Festival (A História do Festival de Brasília do Cinema Brasileiro) - 1965 - 1997, o evento tornou-se o processo cultural mais consistente e duradouro de Brasília, e acompanhou as mudanças sociais, políticas e culturais da cidade.

De acordo com Berê Bahia, a característica inicial do Festival foi o debate de idéias relacionadas ao cinema brasileiro, tentando fazer com que as resoluções ecoassem nos gabinetes, no centro do poder (Bahia, 1998: 21). A pesquisadora diz que a ligação do Paulo Emílio com a universidade foi fundamental para ditar esta face do festival. Até hoje, o evento é considerado o mais polêmico dos festivais de cinema do País.

Ainda segundo a pesquisadora, o evento nasceu da interação dos que falavam de cinema na Universidade de Brasília, dos estudantes da própria universidade e dos assessores da Fundação Cultural do DF, e tornou-se um espaço de projeção para os mais importantes títulos do cinema nacional.

Durante o Festival, são exibidos filmes de longa, média e curta-metragem. Além da mostra competitiva, geralmente fazem parte da programação: retrospectivas de filmes de determinados diretores ou atores, exibição de filmes infantis, debate com cineastas, pesquisadores e outros especialistas, seminários, oficinas e workshops, exposições.

A premiação oficial é feita por meio do troféu Candango, além do prêmio em dinheiro. Os melhores filmes são escolhidos por meio do júri oficial e do júri popular. Também são concedidos prêmios especiais.

Com o advento do Festival de Brasília do Cinema Brasileiro, Brasília tornou-se um dos grandes pólos de produção cinematográfica do País. Em 1991, foi criado, no Distrito Federal, o Pólo de Cinema de Brasília, ligado à Secretaria de Cultura do Distrito Federal. 


\subsection{0 - A Escola vai ao Cinema}

Desde 1999, o Cine Brasília implantou o projeto A Escola vai ao Cinema. Idealizado pelo diretor do Pólo de Cinema de Brasília e coordenador do Festival de Cinema de Brasília, Fernando Adolfo, o projeto é voltado para alunos do Ensino Fundamental de escolas públicas e privadas do Distrito Federal.

As sessões são gratuitas para os alunos das escolas públicas; dos alunos das escolas particulares é cobrado R\$ 1,00 (um real) por cada um. Por meio do projeto, o Cine Brasília cumpre, efetivamente, seu papel de formador de público.

Os filmes exibidos são nacionais e as sessões acontecem de segunda a sexta-feira, às $10 \mathrm{~h}$ e às $15 \mathrm{~h}$, durante os meses de abril a novembro. Um mesmo filme é exibido durante um ano, para que todas as escolas possam levar seus alunos. A Secretaria de Cultura desenvolve o projeto em parceria com a Secretaria de Educação do DF.

A Secretaria de Educação fica encarregada de distribuir os folhetos nas escolas para, posteriormente, os professores agendarem as sessões para os alunos. A Secretaria de Cultura banca o filme e o transporte que leva os alunos ao Cinema.

Segundo Fernando Adolfo, cerca de 120 mil alunos, anualmente, têm a chance de assistir, gratuitamente, a filmes nacionais no Cine Brasília. Como o cinema possui 607 lugares, significa que, por dia, uma média de 1.212 alunos freqüentam as sessões.

Para o coordenador, o projeto estimula a formação de público para o cinema nacional e contribui para a integração social, e funciona como complemento cultural para os estudantes. 


\section{3 - METODOLOGIA DA PESQUISA}

O primeiro passo concreto para elaboração do trabalho, em 2001, foi entrevistar o gerente do Cine Brasília, Antônio Marcos Piza, conhecido por Toninho, e o diretor da Fundação Cultural do Distrito Federal, hoje Secretaria de Cultura do Distrito Federal, Fernando Adolfo.

Por duas vezes, estive pesquisando nos arquivos da FCDF, onde colhi recortes de jornais, relatórios, entre outros papéis importantes. Percebi que há muito pouco material disponível sobre o Cinema e a história inicial de Brasília. Existem apenas pequenas citações e referências ao monumento, mas quase nada de substancial.

Além das entrevistas e do material colhido nos arquivos da antiga Fundação Cultural, a pesquisa contém dados colhidos durante as quatro visitas que fiz ao Cine Brasília - agosto de 2001, julho de 2003, janeiro e março de 2004, para observar e anotar minhas impressões.

Utilizei, ainda, notícias publicadas em jornais, informações do livro 30 Anos de Cinema e Festival (A História do Festival de Brasília do Cinema Brasileiro), coordenado pela pesquisadora Berê Bahia, dados de conversas telefônicas com a própria pesquisadora e o programador José Damata e entrevista com o gerente do Café La Película que funciona nas dependências do Cinema, Marcos Araújo.

No caso das definições sobre turismo, patrimônio histórico, e toda a literatura sobre o assunto, utilizei algumas obras que são citadas nas referências bibliográficas e textos contidos na Internet. 


\section{4 -RESULTADOS DA PESQUISA}

\section{1- Observações sobre a programação}

O Cine Brasília, símbolo do passado cultural da cidade, continua sendo administrado pelo Governo do Distrito Federal. Infelizmente, nos últimos anos, a instituição tem enfrentado alguns problemas, tanto em sua programação quanto em sua estrutura física e material.

O Cine Brasília se sustenta por meio de uma programação cultural e educativa, não visando o lucro, em primeiro lugar. É evidente que os recursos arrecadados pela bilheteria do cinema não são suficientes para investir na conservação, restauração e modernização da instituição, ficando, esse trabalho, a cargo dos cofres do Estado.

O coordenador de cinema da Secretaria de Cultura do Distrito Federal, Fernando Adolfo, afirma que o cinema está ainda em funcionamento, por pertencer ao Governo do Distrito Federal. Ele considera impossível qualquer empresário manter um cinema funcionando com a proposta educativa do Cine Brasília. Segundo ele, a média de público que freqüenta o estabelecimento, varia a cada mês, e que $50 \%$ dos lucros arrecadados, mensalmente, vão para a distribuidora, e, apenas 5\%, vão para o Governo do Distrito Federal

Tudo indica que a programação do Cine Brasília entrou em declínio, com a saída do programador José Damata, que passou a servir aos cinemas da Academia de Tênis e a dedicar-se, com afinco, ao Cinema Voador, um cinema itinerante que percorre vários pontos do Distrito Federal. É certo que um dos grandes motivos que levou os cinéfilos a abandonar o Cine Brasília é que a cidade, nos últimos anos, ganhou muitas salas de cinema alternativo, em especial as inauguradas na Academia de Tênis, ou sob sua administração.

Atualmente, o complexo da Academia de Tênis, administrado pelo senhor Marcos Farani, possui 14 (quatorze) salas de cinema. Os habitantes de Brasília têm alto poder 
aquisitivo, e são consumidores carentes de novidades. É natural que esse público busque uma ampla variedade de consumo, tanto de serviços, como no caso do lazer e da cultura, quanto de produtos.

Os cinemas instalados na própria Academia de Tênis - o complexo mantém, também, uma sala instalada na Cultura Inglesa, e outras três, no Aeroporto-, atraem grande público, porque oferecem as condições de conforto ideais, e dispõem, em seu ambiente, de outros atrativos.

As salas são pequenas e aconchegantes, e dispõem de cadeiras confortáveis, telas de projeção grandes, som excelente e ar-condicionado funcionando na temperatura ideal. O ambiente físico e material é elegante, moderno e confortável, e a programação é variada, indo do comercial ao cult.

Ao contrário do que acontece nas salas dos Cines Academia, que estão em condições materiais desejáveis, infelizmente, o Cine Brasília, como uma grande parte dos empreendimentos gerenciados pelo Estado, apresenta, internamente, e mesmo externamente, aparência de desleixo, abandono e decadência. No subitem 4.3, detalharei as reais condições físicas do estabelecimento.

Além de reclamar da falta de cuidados na conservação física e material da instituição, os antigos freqüentadores do Cine Brasília se queixam, constantemente, da fraca programação oferecida pelo Cinema. Provavelmente, devido ao compromisso assumido pela gerência do Cine Brasília com os realizadores e produtores do cinema nacional, com os quais a administração tem estreito contato, por conta do Festival de Cinema, que acontece, anualmente, é comum o Cinema exibir filmes nacionais, que não atraem os cinéfilos mais exigentes, por períodos um pouco prolongados.

A programação do Cine Brasília também está sendo alimentada por filmes nacionais que foram exibidos à exaustão em outras salas de cinema da cidade, inclusive nas do chamado circuito comercial. É o caso de Deus é Brasileiro, de Cacá Diegues, 
que ficou em cartaz no Cinema boa parte do mês de fevereiro e nos primeiros dias de março, deste ano de 2004.

Nota, publicada no caderno Pensar, do Correio Brasiliense, de 24/01/2004 (ver Anexo $n^{\circ}$ 8), assinada pelo repórter Cláudio Ferreira, reforça a minha observação. Ele se refere à exibição do filme Carandiru, de Hector Babenco, e o Homem que copiava, de Jorge Furtado, que estavam em cartaz no Cine Brasília, depois de terem atraído milhares de cinéfilos em outros cinemas da cidade. É como se o jornalista quisesse dizer: “ mas, que falta de imaginação! O público desejando novidades nas telas de projeção cinematográficas e o Cine Brasília insistindo no que já foi superado, em matéria de público! ”.

A nota do Correio Brasiliense, também reclama da exibição, em janeiro de 2004, do filme infantil Looney Tunes, produção do cinema americano. O repórter considera a fita por demais comercial, enfatizando que a direção do Cinema, certamente, deseja “engordar” o caixa da instituição.

É comum acontecer dos roteiros culturais, publicados nos jornais locais, anunciarem informações erradas a respeito do filme em cartaz no Cine Brasília, ou mesmo o horário em que é exibido. Essa experiência desagradável de chegar ao Cinema para assistir determinado filme, e descobrir que a fita em cartaz é uma outra me aconteceu mais de uma vez. Geralmente, quando vou assistir um filme no Cine Brasília, antes de me dirigir para lá, telefono para a confirmar o anúncio lido no jornal.

Quanto aos erros no horário, acontece, muitas vezes, do jornal anunciar o filme das $17 \mathrm{~h}$ às 19 , e das $19 \mathrm{~h}$ às $17 \mathrm{~h}$. Deve ser porque é comum, uma determinada película iniciar a exibição em um desses horários, e, com o passar do tempo, essa mesma película passa a ser veiculada no horário anterior, ou posterior. Normalmente, os horários de exibição dos filmes no Cine Brasília são 17h, 19h e 21h. 


\section{2- Observações sobre os valores agregados ao serviço prestado}

Quando me referi ao sucesso dos cinemas da Academia de Tênis, sempre lotados, o coordenador de Cinema da Secretaria de Cultura do Distrito Federal, Fernando Adolfo, afirmou que o grande público é atraído para o resort não apenas pela programação cinematográfica, mas pelo que o empreendimento agrega.

Além das salas de cinema, a Academia de Tênis possui uma ampla oferta de atrativos, os chamados valores agregados à prestação de serviços, tão difundidos e defendidos nos trabalhos de marketing empresarial. Restaurantes com gastronomia variada, café, shows musicais, salas com modalidades esportivas, e outros serviços que atraem os freqüentadores.

O Cine Brasília também agrega valores ao serviço principal, que é a exibição de filmes. Há sete anos, funciona no amplo hall do Cinema, o Café La Película. Aberto todos os dias, das $16 \mathrm{~h} 30$ às 23h, o Café, quando começou a funcionar, contava com seis funcionários e sete mesas. Hoje, o serviço conta apenas com um funcionário, o gerente e artista plástico, Marcos Moura, e, no local, existem apenas duas mesas.

O visual do La Película é interessante, mas já apresenta visual de bar meio decadente.. O balcão e as paredes do estabelecimento estão decoradas com cartazes de filmes e fotos de celebridades do mundo do cinema, e, as cadeiras, até pouco tempo, tinham encostos com nomes de cineastas famosos, lembrando as utilizadas no set de filmagens. Existem, também, três ou quatro bancos ao redor do balcão, um deles está com o couro com aparência bem envelhecida. Nada demais, mas colabora para a aparência de descaso e desleixo.

O cardápio é recheado com salgados e guloseimas batizados com nomes de filmes. Mesmo com toda criatividade, o La Película vem acompanhando o estado de abandono e decadência que, atualmente, caracteriza, o Cine Brasília. As cadeiras são poucas e perderam a padronização; os cartazes que compõem a decoração do balcão e 
das paredes estão envelhecidos e, alguns estão soltando os pedaços, o cardápio precisa ser revisto. Antigamente, ainda era possível tomar uma taça de vinho no Café , agora esse produto sumiu da lista de ofertas. O que significa que o empreendimento não é bem administrado. O gerente alega que a mudança ocorreu, devido à diminuição do número de freqüentadores.

Ao lado do La Película, existia duas prateleiras e um balcão funcionando como uma espécie de minilivraria. Havia livros, postais, camisetas, e outros objetos interessantes a serem apreciados pelos clientes e curiosos que iam ao Cinema..De acordo com o gerente do Café, pouco antes da realização do último festival de Cinema, em novembro de 2003, sem maiores explicações, o coordenador da instituição pediu as prateleiras de volta. Resultado, o balcão continua no mesmo lugar, mas vazio; e uma das prateleiras, também vazia, está jogada em um canto, à vista dos visitantes.

\section{3- Observações sobre as condições físicas e materiais do Cinema}

\subsection{1- Área externa do Cinema}

Para elaborar o relatório, estive quatro vezes, como observadora, no Cine Brasília. As visitas foram realizadas em agosto de 2001, julho de 2003, janeiro e março de 2004.

. Anualmente, quando se aproxima o Festival de Brasília do Cinema Brasileiro, o Cinema recebe nova pintura, externa e interna, e também são feitos outros reparos. Mas, pouco tempo depois, as paredes do lado externo já estão pichadas, como aconteceu logo após a realização do último Festival, em novembro de 2003. As paredes de tijolinhos vermelhos já estão cruelmente rabiscadas: tinta preta, em um lado; tinta branca, no outro.

O serviço de limpeza nem sempre opera com regularidade na área externa do Cinema. Em muitas ocasiões, tem muito lixo na calçada. Às vezes, os resíduos estão 
acoplados em sacos de lixo, esperando a passagem do carro de limpeza urbana. Outras vezes, o lixo encontra-se espalhado e até mesmo, ficam acumulados nos bueiros localizados na calçada. Em uma das visitas, percebi que dos seis bueiros, três estavam entupidos com lixo.A lixeira que dá para a SQS 107 está bastante enferrujada.

. A bilheteria do lado da SQN 107 não funciona há bastante tempo.

A área de estacionamento para carros é ampla, pois o cinema, raramente, fica lotado, a não ser nos dias em que acontece o Festival de Brasília do Cinema Brasileiro.

\subsection{2 - Área interna do Cinema}

. Algumas cadeiras foram trocadas por outras mais novas, principalmente as que ficam no centro da sala de exibição. Por outro lado, há locais que dá a impressão de estar faltando alguma poltrona. O coordenador do Cinema, Fernando Adolfo, disse que alguns dos alunos que participam das sessões do projeto A Escola vai ao cinema algumas vezes promovem algazarras durante as sessões, chegando, às vezes, a danificar as poltronas.

. O carpete está cada dia mais envelhecido, manchado e com cheiro de mofo, o que é desagradável para os olhos e o nariz dos freqüentadores, e um sério perigo para as pessoas que são alérgicas.Fernando Adolfo disse que, para trocar o carpete, o Cinema teria que ficar uns seis meses sem funcionar, o que acarretaria grande perda financeira para os cofres da instituição.

Existem quatro banheiros que podem ser utilizados pelo público do Cine Brasília. Dois ficam na área da grande sala de projeção, e os outros dois ficam no hall. Dois femininos, dois masculinos. Não visitei nenhum dos banheiros masculinos. 
O banheiro feminino da sala de projeção está em bom estado. As três portas dos sanitários estão conservadas, as pias, vasos, espelhos, descargas, cestos de colocar papel, também. A iluminação está normal.

O banheiro feminino do hall está com espelho, pias, cestos de papel, iluminação, descargas conservadas, mas uma das portas de um dos dois banheiros está com a pintura descascando e, ambas, estão sem trancas há muitos anos.

.No hall, existe apenas um orelhão e dois bebedouros.

. O teto da entrada principal está descascando.

.Os bancos acarpetados, que ficam na área do hall, estão com a aparência envelhecida. 


\section{5- CONCLUSÃO}

\section{1- O cinema como patrimônio histórico}

O Cine Brasília precisa voltar a fazer parte, de forma mais efetiva, do lazer cultural dos habitantes de Brasília, pois a instituição é parte da memória coletiva da cidade. Por meio de sua história, é possível compreender a vida artística e cultural que reinou na Capital da República, nos primeiros tempos de sua existência. Sua significação é valiosa como símbolo da identidade local, partindo, inclusive, do nome como foi batizado - o mesmo da nova Capital.

O Cinema é propriedade do Estado, e deve permanecer sob sua responsabilidade. A instituição não pode correr o risco de passar para as mãos da iniciativa privada, como aconteceu no passado, nos primeiros anos de funcionamento. A instituição deve conservar sua identidade histórica e cultural, e sua função de projetar filmes de boa qualidade, colaborando, assim, na formação de público interessado na arte cinematográfica, como acontece com o projeto A Escola vai ao Cinema e o Festival de .Brasília do Cinema Brasileiro.

Se o Cinema for arrendado por empresas que visam apenas o lucro, poderá repetir a história dos primeiros tempos de sua inauguração, época em que ficou sob a responsabilidade da Companhia Cinematográfica Luiz Severiano Ribeiro. Além de investir em uma programação comercial, os arrendatários cuidaram mal da instituição.

Não há intenção de que o Cinema deva ser sustentado pela atividade turística, até mesmo porque essa atividade não atingiu níveis satisfatórios no Distrito Federal, muito menos no que se refere ao turismo cultural. A instituição terá que continuar sobrevivendo por meio dos recursos transferidos pelo Estado, e pela arrecadação da bilheteria. A não ser que a instituição fosse beneficiada pela implementação de algum projeto do Governo do Distrito Federal em parceria com o Governo federal ou com 
empresa privada, que tivesse como objetivo a atividade turística ou a recuperação do patrimônio histórico.

O Distrito Federal vem despontando como grande receptor do turismo de negócios e de eventos. Representantes do trade turístico local têm acalentado o sonho de desenvolver, na região, o turismo cívico, que levaria à valorização de muitos monumentos e edificações da cidade.

O Cine Brasília não é um símbolo cívico de exaltação nacional, mas, poderia ser revalorizado, pela população local, por meio de ações desenvolvidas no âmbito do turismo cívico. A partir do momento em que projetos e programas implantados pelo Governo distrital, com apoio do Governo federal, começarem a despertar na sociedade brasileira o sentimento de valorização e profundo respeito pelos símbolos nacionais e de memória, naturalmente, tudo que está ligado à história do País e da cidade receberá maior atenção, não só por parte do Governo, mas também da comunidade a qual pertence o bem. Naturalmente, a valorização de um monumento com forte referência histórica local chamaria a atenção dos visitantes e eles, naturalmente, passariam a valorizar esse bem com o valor devido.

O Cinema deveria ser valorizado em publicações voltadas para o segmento turístico, pois desconheço a divulgação da instituição em material importante editado para os turistas que visitam a Capital, como guias da cidade, folhetos, folders, postais. Mesmo nos catálogos telefônicos do Distrito Federal que, editados anualmente, exploram as atrações turísticas locais, não existe boa divulgação do Cinema como ponto turístico. 


\section{2 - O Cinema e sua programação}

Se a administração do Cine Brasília quiser enfrentar a concorrência com as inúmeras salas de cinema alternativo do Distrito Federal, deve começar a investir na recuperação, conservação e modernização da estrutura física e material da instituição, na revitalização da programação e na valorização dos serviços agregados ao bem.

As produções cinematográficas nacionais são o eixo do Festival de Brasília do Cinema Brasileiro, o mais importante evento realizado, anualmente, no Cine Brasília. Depois de vários anos sobrevivendo com baixo orçamento da União, minguado incentivo e estímulo governamental, o cinema nacional tomou fôlego e vem despertando nos apreciadores de cinema interesse pelo que vem produzindo.

Não é à toa que, inúmeros filmes brasileiros têm sido indicados ao Oscar, o mais importante prêmio do cinema americano, pois boa parte da produção cinematográfica nacional tem lotado as salas de cinema do País. Isso demonstra o alto nível a que chegou essa indústria.

É óbvio que, para atrair o público, os filmes produzidos no Brasil também são alvos de pesadas campanhas publicitárias. Mesmo assim, a tarefa de levar o público local a se interessar pelo cinema nacional não foi fácil, pois se trata de um público refém da indústria cinematográfica produzida nos Estados Unidos, caracterizada pela alta qualidade técnica, glamour, entretenimento e sofisticados efeitos visuais.

O recente interesse do público brasileiro pelo cinema produzido no Brasil é importante e compensador para os diretores e produtores da indústria cinematográfica nacional, pois estimula esses profissionais a produzirem fitas de qualidade, a utilizarem recursos com alta tecnologia e a elaborarem roteiros com valor artístico, cultural, e mesmo, comercial. Essa nova fase do cinema brasileiro também é muito boa para os proprietários de salas de cinema. 
É natural que, com toda a expansão da indústria do cinema no Brasil, os donos e administradores de salas de cinema se sintam obrigados a investir no cinema brasileiro. A gerência do Cine Brasília, por pertencer ao Estado e promover um Festival nacional anual de cinema, deve, ainda mais, se sentir tentada a investir nesse produto. Cabe lembrar, que o projeto A Escola vai ao cinema, também, só exibe filmes nacionais.

Mesmo com todo o compromisso com a produção do cinema nacional, a administração do Cine Brasília deve evitar exibir filmes que não tenham valor artístico e cultural. A administração não deve se deixar guiar pelos “caprichos” de determinados produtores e diretores de cinema, que desejam exibir suas fitas naquele espaço, mesmos quando esses filmes não têm grande apelo junto ao um público relativamente exigente.

A gerência do Cinema deve evitar, ainda, projetar filmes nacionais, ou de qualquer outro País, que tenha tido grande sucesso de bilheteria, recentemente, pois, além de deixar a sala de cinema vazia, vai parecer que a exibição visa apenas o lucro, e não o padrão cultural.

É muito importante ampliar e mesclar a programação. Filmes recentes; filmes antigos. Produções nacionais; produções estrangeiras variadas: francesa, chinesa, inglesa, iraniana, canadense, argentina, belga, vietnamita, africana, mexicana etc. Mas, as fitas exibidas devem obedecer a um alto padrão de escolha, de estratégia.

Eventos como a Semana da Francofonia, que vem acontecendo no Cinema, anualmente, com a finalidade de mostrar produções de países de língua francesa, devem ser estimuladas pela administração do Cine Brasília.

Os responsáveis pelo Cinema não devem ignorar as informações veiculadas nos roteiros culturais, publicados nos jornais editados na cidade. O acompanhamento vai evitar erros no anúncio da programação. Muitas vezes, o filme anunciado no jornal não corresponde ao que está em cartaz. Também ocorre erro no anúncio do horário de exibição e, até mesmo, na sinopse de determinado filme. 


\section{3-A importância da conservação do Cinema e os serviços agregados}

O sucesso dos Cinemas da Academia de Tênis deveria servir de modelo e de alerta para a administração do Cine Brasília. É necessário investir, tanto na programação quanto na melhoria das condições físicas e materiais do Cinema. Para evitar a deterioração da estrutura física e material das instalações, causada pela ação do tempo, é preciso não descuidar da conservação, manter o que já existe e empregar novos recursos na aquisição de novos equipamentos e tudo o que for importante para revitalizá-lo. A pintura feita, anualmente, pouco antes da realização do Festival de Cinema, é apenas um detalhe nesse processo.

O vandalismo que impera no Distrito Federal, em especial o que promove a pichação, está longe de ser combatido. Ainda não foi tomada nenhuma medida drástica contra esses agressores do patrimônio público e privado. É necessário que o Estado crie mecanismos efetivos capazes de coibir a ação desses inimigos da ordem e da harmonia estética urbana.

Os estabelecimentos e prédios da iniciativa privada quando são agredidos pelos pichadores, automaticamente, os proprietários tratam de resolver o problema mandando fazer nova pintura. O Estado tem atitude diferente. Quando os monumentos e instituições estatais são vítimas dos pichadores, nem sempre uma nova pintura é feita de imediato, pois há sempre a velha história de que o Estado não tem recursos suficientes para fazer o reparo. É o que acontece com o Cine Brasília. A pichação que é feita logo após o término do Festival, parece se estender até o próximo evento.

O serviço de limpeza deveria operar, com regularidade, na área do cinema. A administração da instituição deve cobrar esse serviço, que, apesar de ser terceirizado, é contratado e pago pelo Estado. 
O bom funcionamento do Café La Película, ou um outro que possa vencer uma nova licitação, e a implantação de uma e verdadeira livraria ajudariam bastante a revitalizar o Cinema.

A licitação de locais como esses deve privilegiar pessoas que desejam realmente investir no negócio que está sendo implantado, montado, e não contemplar amigos e conhecidos de pessoas que ocupam cargos importantes no Governo, atitude comum nos negócios que envolvem o Estado brasileiro, seja nas esferas federal, estadual e municipal.

Para poder atender os estudantes do projeto A Escola vai ao cinema, o Café teria que começar a funcionar no horário da manhã, de segunda -feira a sexta-feira. Fecharia no horário de almoço e voltaria a funcionar no horário da tarde. O cardápio da manhã seria composto de lanches destinado à meninada, como pão de queijo, sanduíche, iogurte e chocolate líquido, no período da tarde, ofereceria produtos mais do agrado dos adultos, como sanduíches mais incrementados , vinho, cerveja. Uma oferta bem variada.

A livraria teria que vender livros, catálogos, camisetas, pôsteres, e outros objetos relacionados ao universo do cinema. Seria mais uma novidade capaz de atrair o público para o Cine Brasília. Tudo isso combinado com uma boa programação de filmes e um ambiente bem cuidado e confortável. 


\section{4 - CONCLUSÃO FINAL}

A forma efetiva e real para recuperar, revitalizar e conservar o Cine Brasília seria tratar, passo a passo, cada detalhe no que diz respeito ao ambiente, à programação e aos serviços agregados. Com sensibilidade administrativa, verificar o que precisa ser feito, melhorado, mudado e revitalizado.

É necessário não descuidar das mínimas coisas. Olhar ao redor e descobrir o que os freqüentadores desejam, sonham. Observar a concorrência e tirar alguma lição positiva e aplicá-la. A arte e a cultura são dinâmicas, não estáticas, e todo espaço que sobrevive das duas coisas não pode se render à passividade, à mesmice, à falta de idéias e de criatividade e, muito menos, à apatia. Infelizmente, o Estado tende a ser apático e burocrático, e essas duas coisas atrapalham a evolução, a expansão e a modernização.

Antes de tudo, é responsabilidade do Estado e da comunidade zelar pelo patrimônio histórico e cultural Quando um Governo adota medidas para proteger um bem público, os bons resultados são visíveis e sua administração torna-se confiável e demonstra o grau de consciência do Estado com relação ao Patrimônio Histórico. A atitude governamental orgulha a sociedade da qual é o dirigente, e o bem é apreciado pela comunidade onde está inserida e pelos turistas que o visitam. A identidade de uma nação pode ser definida pelos seus monumentos - aquele conjunto de bens culturais associados ao passado nacional (GONÇALVES, 1988, p.267, apud Margarita Barretto).

Antes de encerrar a pesquisa, vale lembrar que circula pelas cidades e recantos do mundo, uma importante figura a qual denominamos Flanêur "esse passeador que anda a esmo e se perde na multidão, sem destino, seguindo para onde o capricho ou a curiosidade direcionam seus passos (WHITE, p. 23, 2002).

Esse passeador descobre locais inusitados e é um grande propagador da imagem e dos pontos turísticos de um lugar. Por isso, é importante que os locais e objetos que compõem o Patrimônio Histórico e Cultural das cidades estejam bem cuidados e 
preservados, para serem contemplados pelos olhos do Flanêur, dos habitantes e dos turistas comuns. 


\section{6- REFERÊNCIAS BIBLIOGRÁFICAS}

- BAHIA, Berê. Trinta anos de cinema e festival - a história do festival de Brasília do cinema brasileiro, 1965/1997, Brasília, Fundação Cultural do Distrito Federal, 1998.

- BARBOSA, Ycarim Melgaço. O despertar do turismo -um olhar crítico sobre os não-lugares, São Paulo, Alephi, 2001.

- BARRETTO, Margarita. Turismo e Legado Cultural, Campinas, Papirus,2000.

- BERBEL, Joatan Vilela. Ativo cultural: um outro paradigma para as políticas públicas de cultura. Texto publicado no site Google, janeiro 2004.

- BRASIL.Instituto de Patrimônio Histórico e Artístico Nacional (Iphan)/ Ministério da Cultura.Boletim Informativo editado pela $14^{\text {a }}$ Superintendência Regional, Brasília, novembro/dezembro, 1992.

- BUARQUE, Aurélio. Minidicionário, Rio de Janeiro, Nova Fronteira, 1977.

- FUNARI, Pedro Paulo e PINSKY, Jaime (org.).Turismo e Patrimônio Cultural, São Paulo, Contexto, 2001.

- IPHAN. Site:www.iphan.gov.br, em 13/01/2004.

- TRIGO, Luiz Gonzaga Godoi. Turismo e Qualidade tendências contemporâneas, Campinas, Papirus, 1993.

- WHITE, Edmund. O Flanêur - Um passeio pelos paradoxos de Paris, São Paulo, Companhia das Letras, 2001. 